\title{
Efficacy and association analysis of high-dose methotrexate in the treatment of children with acute lymphoblastic leukemia
}

\author{
FANGWEI GONG ${ }^{1}$, QINGJUN MENG ${ }^{1}$, CHENGJUAN LIU $^{1}$ and YEQI ZHAO ${ }^{2}$ \\ ${ }^{1}$ Ward 2, Department of Pediatrics and ${ }^{2}$ Ward 6, Department of Pediatrics, The People's \\ Hospital of Pingyi County, Linyi, Shandong 273300, P.R. China
}

Received September 11, 2018; Accepted February 15, 2019

DOI: $10.3892 / \mathrm{ol} .2019 .10128$

\begin{abstract}
Effect of high-dose methotrexate (MTX) on children with acute lymphoblastic leukemia (ALL) with different subtypes and disease courses was investigated. A retrospective analysis of 207 children with ALL who were admitted to the People's Hospital of Pingyi County from March 2014 to June 2017 was carried out. According to the subtype of the disease, the children were divided into two groups. B-lineage group: ALL occurred in B-lineage lymphocytes $(n=128)$; T-lineage group: ALL occurred in T-lineage lymphocytes $(n=79)$. According to the disease course, the children were divided into three groups. High-risk group: disease course $>15$ days $(n=67)$; moderate-risk group: disease course $>8$ and $<15$ days $(n=58)$; low-risk group: disease course $<8$ days $(n=82)$. The plasma concentration, calcium formyltetrahydrofolate (CF) rescue times and adverse reactions were compared at $12 \mathrm{~h}$ (T1), $48 \mathrm{~h}$ (T2), and $72 \mathrm{~h}$ (T3) after MTX infusion. The plasma concentration in B-lineage group was significantly higher than that in the T-lineage group at T2 and T3 $(\mathrm{P}<0.05)$. The incidence of adverse reactions in children with ALL in the B-lineage group was significantly higher than that in the T-lineage group $(\mathrm{P}<0.05)$. The $\mathrm{CF}$ rescue times in high-risk group were more than that in moderate- and low-risk groups $(\mathrm{P}<0.05)$. The incidence of adverse reactions in the high-risk group was significantly higher than that in the moderate- and low-risk groups $(\mathrm{P}<0.05)$, and in the moderate-risk group was significantly higher than that in the low-risk group $(\mathrm{P}<0.05)$. Compared with T-lineage ALL children, high-dose MTX causes more toxic injury to B-lineage ALL children. During clinical application of MTX in the treatment of ALL, close attention should be paid to the changes of the vital signs of patients, and timely CF rescue should be performed.
\end{abstract}

Correspondence to: Dr Yeqi Zhao, Ward 6, Department of Pediatrics, The People's Hospital of Pingyi County, 7 Jinhua Road, Linyi, Shandong 273300, P.R. China

E-mail: ym46yt@163.com

Key words: high-dose methotrexate, acute lymphoblastic leukemia, calcium formyltetrahydrofolate, efficacy observation

\section{Introduction}

Acute lymphoblastic leukemia (ALL) has an extremely rapid progression and is more common in children aged 3-7 years (1). According to statistics, ALL accounts for $\sim 80 \%$ of leukemia, and this number is rising year by year (2). Data show that, in 2016, the number of new ALL patients in the world exceeded 2.1 million, and the cumulative number of patients reached $>300$ million $(3,4)$. Because of the rapid progression of ALL, there is a high probability of death caused by the absence of effective treatment within 5-10 days after its onset (5). As there are no obvious special symptoms in the early stages of ALL, many patients often miss the best treatment period because of limited medical general knowledge or because they are misdiagnosed, which is also one of the key problems that lead to poor long-term prognosis in ALL (6). It has been reported that the 5-year survival rate of the prognosis of ALL patients corresponds to only 20-40\% (7). Because of its high incidence and high risk, ALL has been included in the key research of disease, but its pathogenesis has not yet obtained breakthrough research results. In clinic, methotrexate (MTX) is the most common drug in the treatment of leukemia, lymphadenoma, osteosarcoma and other autoimmune diseases (8).

MTX, an oncology drug of antifolate metabolism, that has a similar chemical structure to folic acid and can inhibit DNA synthesis by inhibiting the activity of dihydrofolate reductase in cells, has been proven to have a high application value in ALL (9-11). With the deepening of research, an increasing number of scholars worldwide consider that the efficacy of high-dose MTX in the treatment of ALL is more significant (12-14). However, most of the current studies are limited to the wide application of MTX, and there is little research on the exact effect of MTX in the treatment of ALL patients with different subtypes and different disease courses. Since 2014, the People's Hospital of Pingyi County (Linyi, China) has begun to promote the use of MTX in clinical practice as the first choice for the treatment of ALL, and has accumulated a large number of sample cases. Therefore, by comparing efficacy differences of high-dose MTX in ALL patients with different subtypes and disease courses, the efficacy of high-dose MTX in the treatment of ALL was studied in depth to provide reference and guidance for clinical practice. 
Table I. Clinical data of children with different subtypes [n (\%)].

\begin{tabular}{|c|c|c|c|c|}
\hline Factor & $\begin{array}{l}\text { B-lineage group } \\
\quad(\mathrm{n}=128)\end{array}$ & $\begin{array}{c}\text { T-lineage group } \\
(\mathrm{n}=79)\end{array}$ & $\chi^{2}$ or $t$ value & P-value \\
\hline Age (years) & $5.94 \pm 3.11$ & $6.23 \pm 2.97$ & 0.663 & 0.508 \\
\hline Body weight (kg) & $27.62 \pm 8.94$ & $28.92 \pm 9.14$ & 1.008 & 0.315 \\
\hline Living environment & & & 0.451 & 0.502 \\
\hline Urban & $75(58.59)$ & $50(63.29)$ & & \\
\hline Rural & $53(41.41)$ & $29(36.71)$ & & \\
\hline Only child & & & 0.044 & 0.834 \\
\hline Yes & $71(55.47)$ & $45(56.96)$ & & \\
\hline No & $57(44.53)$ & $34(43.04)$ & & \\
\hline Family history of hereditary diseases & & & 0.076 & 0.783 \\
\hline Yes & $35(27.34)$ & $23(29.11)$ & & \\
\hline No & $93(72.66)$ & $56(70.89)$ & & \\
\hline First onset & & & 0.131 & 0.718 \\
\hline Yes & $96(75.00)$ & $61(77.22)$ & & \\
\hline No & $32(25.00)$ & 18 (22.79) & & \\
\hline
\end{tabular}

\section{Patients and methods}

Patients. A retrospective analysis of 207 children with ALL, treated with high-dose MTX in The People's Hospital of Pingyi County from March 2014 to June 2017, was carried out, including 124 males and 83 females, with an age range of 3-11 years and an average age of $6.13 \pm 3.27$ years. Inclusion criteria: children conforming to the clinical manifestations of ALL (15) and diagnosed with ALL in the People's Hospital of Pingyi County; children with complete data; children not receiving related medical treatment in other hospitals. Exclusion criteria: children unwilling to receive relevant medical treatment; children allergic to drugs; children with other serious cardiovascular diseases or tumors; children with severe liver and renal insufficiency; children with communication or cognitive impairment. This study was approved by the Ethics Committee of the People's Hospital of Pingyi County. Guardians of the patients signed informed consent and agreed that the tissue of the patient could be used in this study, and cooperated with the medical staff to complete the diagnosis and treatment.

Main reagents. MTX was purchased from Beijing Baiaolaibo Technology Co., Ltd., Beijing, China (cat. no. QN0838-IKA). Dexamethasone was purchased from Hubei Yuancheng Saichuang Technology Co., Ltd., Wuhan, China (cat. no. 50-02-2). Cytosine arabinoside was purchased from Shanghai Baoman Biotechnology Co., Ltd., Shanghai, China (cat. no. N0072). Calcium formyltetrahydrofolate (CF) was purchased from Shanghai Yijing industrial Co., Ltd., Shanghai, China (cat. no. 151533-22-1).

Methods. All patients received chemotherapy according to the 2013 Leukemia Diagnosis and Treatment Guidelines (16). Intravenous infusion of $1 / 6$ of the total amount of MTX ( $\leq 500 \mathrm{mg}$ each time) was performed within $30 \mathrm{~min}$, and the remaining 5/6 was administered within $24 \mathrm{~h}$. A triple sheath injection was performed $1 \mathrm{~h}$ after the infusion of the first $1 / 6$ MTX (including MTX $12.5 \mathrm{mg}$, dexamethasone $5 \mathrm{mg}$, cytosine arabinoside $35 \mathrm{mg})$. CF rescue $\left(15 \mathrm{mg} / \mathrm{m}^{2}\right)$ was performed after $12 \mathrm{~h}$ of complete infusion of MTX, and in the case of delayed excretion, the number and dose of CF rescue were increased. Sufficient hydration $\left(3 \mathrm{l} / \mathrm{m}^{2}\right)$ and urine alkalization $(\mathrm{pH}>8)$ were conducted on the same day and 3 days after administration. The changes of the vital signs in children were monitored during chemotherapy. Venous blood $(2 \mathrm{ml})$ was drawn in the anticoagulant tube on an empty stomach at $12 \mathrm{~h}$ (T1), $48 \mathrm{~h}$ (T2), $72 \mathrm{~h}$ (T3) after infusion, and separated by centrifuging at $2,500 \mathrm{x}$ g for $15 \mathrm{~min}$ at $4^{\circ} \mathrm{C}$ to collect serum. The concentration of MTX in the serum of children and the adverse reactions were determined by Siemens Viva-E automatic drug concentration monitoring system (Siemens AG, Munich, Germany), including bone marrow suppression, gastrointestinal reaction and liver function injury.

Statistical analysis. SPSS 24.0 software (Beijing Strong Vinda Information Technology Co., Ltd., Beijing, China) was used for statistical analysis. The clinical enumeration data of children with different subtype of ALL and different course of disease were expressed as percentage [n (\%)] and analyzed using $\chi^{2}$ test. The measurement data were expressed as mean \pm standard deviation and t-test was used for their comparison. $\mathrm{F}$ analysis was used to compare the differences between multiple groups. LSD test was used as a post hoc test. $\mathrm{P}<0.05$ was considered to indicate a statistically significant difference.

\section{Results}

Comparison of clinical data of ALL children with different subtypes. Of the 207 children, there were 128 cases of B-lineage (B-lineage group) and 79 cases of T-lineage (T-lineage group). There was no significant difference between the two groups of patients regarding the clinical data of age, body weight, living 
Table II. Adverse reactions in children with different subtypes [n (\%)].

\begin{tabular}{lcccr}
\hline Adverse reaction & $\begin{array}{c}\text { B-lineage group } \\
(\mathrm{n}=128)\end{array}$ & $\begin{array}{c}\text { T-lineage group } \\
(\mathrm{n}=79)\end{array}$ & $\chi^{2}$ value & P-value \\
\hline Bone marrow suppression & $11(8.59)$ & $3(3.80)$ & 1.782 & 0.182 \\
Gastrointestinal reaction & $37(28.91)$ & $16(20.25)$ & 1.920 & 0.166 \\
Skin allergic reaction & $12(9.38)$ & $6(7.60)$ & 0.195 & 0.659 \\
Liver function injury & $8(6.25)$ & $2(2.53)$ & 1.469 & 0.226 \\
Respiratory tract reaction & $16(12.5)$ & $7(8.86)$ & 0.655 & 0.418 \\
Adverse reaction rate $(\%)$ & $84(65.63)$ & $34(43.04)$ & 10.170 & 0.001 \\
\hline
\end{tabular}

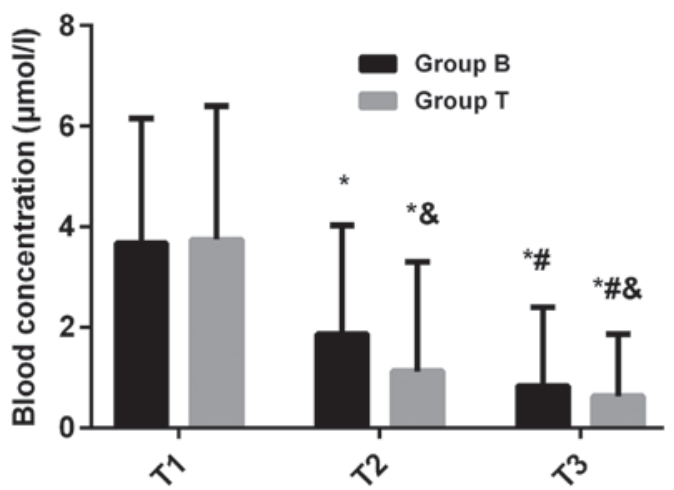

Figure 1. Plasma concentration in serum of ALL children with different subtypes. There was no significant difference in plasma concentration between the two groups at T1 $(\mathrm{P}>0.05)$. The plasma concentration in B-lineage group was significantly higher than that in $\mathrm{T}$-lineage group at $\mathrm{T} 2(\mathrm{P}<0.05)$. The plasma concentration in B-lineage group was also significantly higher than that in $\mathrm{T}$-lineage group at $\mathrm{T} 3(\mathrm{P}<0.05)$. The plasma concentration at $\mathrm{T} 2$ was lower than that at $\mathrm{T} 1$, and at $\mathrm{T} 3$ was lower than at $\mathrm{T} 2$ in both groups $(\mathrm{P}<0.05)$. ${ }^{*} \mathrm{P}<0.05$, compared with $\mathrm{T} 1$ in the same group; ${ }^{\#} \mathrm{P}<0.05$, compared with $\mathrm{T} 2$ in the same group; ${ }^{\&} \mathrm{P}<0.05$, compared with the $\mathrm{B}$ lineage group at the same time. ALL, acute lymphoblastic leukemia.

environment, whether he/she was the only child, whether there was a family history of hereditary disease, and whether it was the first onset $(\mathrm{P}>0.05)$, proving that the two groups of patients were comparable (Table I).

Comparison of plasma concentration and $C F$ rescue times in ALL children with different subtypes. There was no significant difference in plasma concentration between the two groups at $\mathrm{T} 1(\mathrm{P}>0.05)$. The plasma concentration in B-lineage group $(1.86 \pm 2.17 \mu \mathrm{mol} / \mathrm{l})$ was significantly higher than that in T-lineage group $(1.12 \pm 2.18 \mu \mathrm{mol} / \mathrm{l})$ at $\mathrm{T} 2(\mathrm{P}<0.05)$. The plasma concentration in B-lineage group $(0.83 \pm 1.57 \mu \mathrm{mol} / \mathrm{l})$ was also significantly higher than that in T-lineage group $(0.62 \pm 1.24 \mu \mathrm{mol} / \mathrm{l})$ at $\mathrm{T} 3(\mathrm{P}<0.05)$. The plasma concentration at T2 was significantly lower than that at T1, and at T3 was lower than that at $\mathrm{T} 2$ in both groups $(\mathrm{P}<0.05)$. There was no significant difference in $\mathrm{CF}$ rescue times between B-lineage group (8.17 \pm 4.58 times) and T-lineage group (8.26 \pm 5.03 times) (P>0.05) (Figs. 1 and 2).

Comparison of adverse reactions in ALL children with different subtypes. The incidence of adverse reactions in children with ALL in B-lineage group was significantly higher than

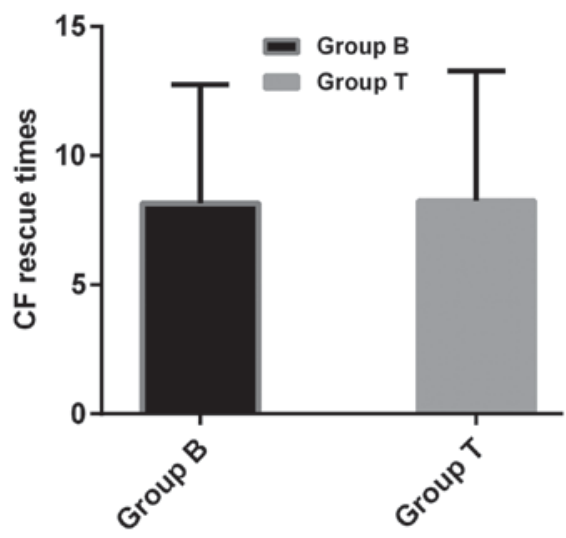

Figure 2. CF rescue times in children with different subtypes. There was no significant difference in $\mathrm{CF}$ rescue times between the B-lineage group and the T-lineage group $(\mathrm{P}>0.05)$. $\mathrm{CF}$, calcium formyltetrahydrofolate.

that in the T-lineage group, and the difference was statistically significant $(\mathrm{P}<0.05)$ (Table II).

Comparison of clinical data of children with different disease courses. According to the disease course, the children were divided into three groups. High-risk group: disease course $>15$ days $(n=67)$; moderate-risk group: disease course $>8$ and $<15$ days $(n=58)$; low-risk group: disease course $<8$ days $(n=82)$. There was no significant difference between the three groups in the clinical data of age, body weight, living environment, whether he/she was the only child, whether there was a family history of hereditary disease, and whether it was the first onset ( $P>0.05)$, confirming that the three groups of patients were comparable (Table III).

Comparison of plasma concentration and $C F$ rescue times in children with different disease courses. There was no significant difference in plasma concentration at T1, T2 and T3 between the three groups $(\mathrm{P}>0.05)$. The plasma concentration at $\mathrm{T} 2$ was lower than that at $\mathrm{T} 1$, and at $\mathrm{T} 3$ was lower than that at $\mathrm{T} 2$ in the three groups, and the differences were statistically significant $(\mathrm{P}<0.05)$. The $\mathrm{CF}$ rescue times in high-risk group $(9.57 \pm 5.16$ times) were more than that in moderate-risk group $(7.63 \pm 4.66$ times) and low-risk group (6.37 \pm 3.58 times), and the differences were statistically significant $(\mathrm{P}<0.05)$ (Figs. 3 and 4$)$.

Comparison of adverse reactions in children with different disease courses. The incidence of a gastrointestinal reaction, 
Table III. Clinical data of children with different disease courses [n (\%)].

\begin{tabular}{|c|c|c|c|c|c|}
\hline Factor & $\begin{array}{c}\text { High-risk } \\
\text { group }(n=67)\end{array}$ & $\begin{array}{l}\text { Moderate-risk } \\
\text { group }(n=58)\end{array}$ & $\begin{array}{c}\text { Low-risk } \\
\text { group }(\mathrm{n}=82)\end{array}$ & $\mathrm{F} / \chi^{2}$ value & P-value \\
\hline Age (years) & $5.32 \pm 2.86$ & $6.17 \pm 2.35$ & $5.81 \pm 3.02$ & 1.467 & 0.233 \\
\hline Body weight (kg) & $26.69 \pm 7.37$ & $27.36 \pm 7.84$ & $28.23 \pm 8.58$ & 0.694 & 0.501 \\
\hline Living environment & & & & 0.574 & 0.615 \\
\hline Urban & $37(55.22)$ & $35(60.34)$ & $53(64.63)$ & & \\
\hline Rural & $30(44.78)$ & $23(39.66)$ & $29(35.37)$ & & \\
\hline Only child & & & & 1.068 & 0.447 \\
\hline Yes & $35(52.24)$ & $39(67.24)$ & $42(51.22)$ & & \\
\hline No & $32(47.76)$ & $19(32.76)$ & $40(48.78)$ & & \\
\hline Family history of hereditary diseases & & & & 0.150 & 0.867 \\
\hline Yes & $23(34.33)$ & $14(24.14)$ & $21(25.61)$ & & \\
\hline No & $44(65.67)$ & $44(75.86)$ & 61 (74.39) & & \\
\hline First onset & & & & 0.094 & 0.913 \\
\hline Yes & $46(68.66)$ & $40(68.97)$ & 71 (86.59) & & \\
\hline No & $21(31.34)$ & $18(31.03)$ & $11(13.41)$ & & \\
\hline
\end{tabular}

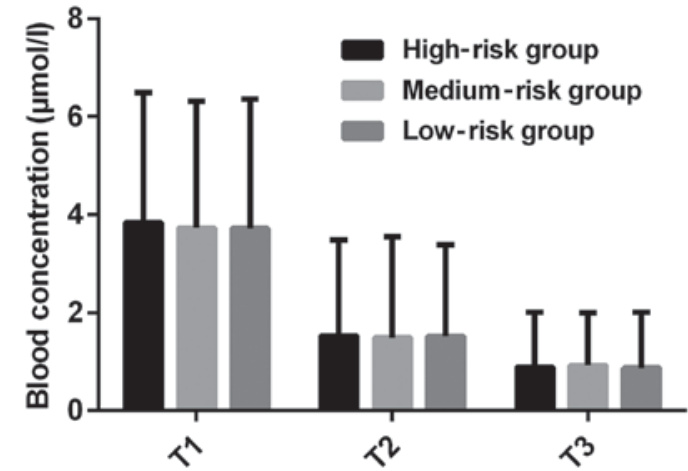

Figure 3. Plasma concentrations of ALL children with different disease courses. There was no significant difference in plasma concentration at $\mathrm{T} 1$, $\mathrm{T} 2$ and $\mathrm{T} 3$ between the three groups $(\mathrm{P}>0.05)$. The plasma concentration at $\mathrm{T} 2$ was lower than that at T1, and at T3 was lower than at T2 in all the three groups $(\mathrm{P}<0.05)$. ALL, acute lymphoblastic leukemia.

skin allergic reaction and respiratory tract reaction, as well as the adverse reaction rate in the high- and moderate-risk groups were significantly higher than that in the low-risk group $(\mathrm{P}<0.05)$. Also, the adverse reactions rate in the high-risk group was significantly higher than that in the low-risk group $(\mathrm{P}<0.05)($ Table IV).

\section{Discussion}

As an antifolate metabolite, MTX combined with dihydrofolate reductase can inhibit the conversion of dihydrofolic acid to tetrahydrofolic acid, block the synthesis of pyrimidine and purine, inhibit the synthesis of DNA, thus achieving an antitumor effect (17). MTX is usually not able to penetrate the blood-brain barrier and is difficult to be detected in cerebrospinal fluid during tumor therapy (18). To achieve the goal of treating leukocyte, the concentration of MTX in cerebrospinal fluid needs to be $>10^{7} \mu \mathrm{mol} / 1$, at which time

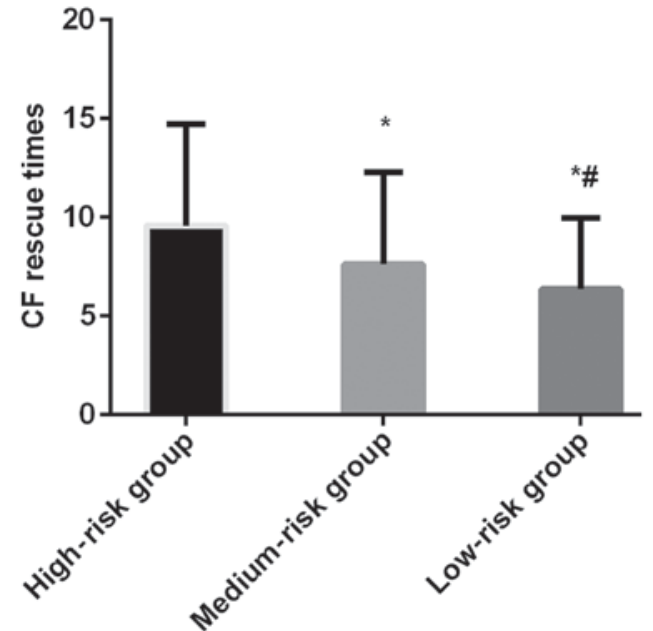

Figure 4. CF rescue times in children with different disease courses. The $\mathrm{CF}$ rescue times in high-risk group were more than that in moderate-risk group and low-risk group $(\mathrm{P}<0.05)$. ${ }^{*} \mathrm{P}<0.05$, compared with the $\mathrm{CF}$ rescue times in the high-risk group; ${ }^{\#} \mathrm{P}<0.05$, compared with the $\mathrm{CF}$ rescue times in the moderate-risk group. $\mathrm{CF}$, calcium formyltetrahydrofolate.

the inhibitory effect on the synthesis of DNA in leukemic cells could be completed (19). Therefore, the dosage of MTX needs to be increased. When MTX is highly concentrated and continuously injected into the patient's body, it can enter the cells through the reductive folate carrier on the cell membrane, thus affecting leukemic cells (20). MTX can affect leukemic cells, but also produce toxicity to normal cells of patients, so it is necessary to carry out CF rescue in the treatment of MTX (21), which can reduce the toxicity of MTX and increase the effectiveness of the treatment by providing tetrahydrofolate coenzyme to the normal cells of the patient (22).

In the present study, the analysis on the efficacy differences of high-dose MTX in ALL patients with different subtypes and disease courses showed that the plasma concentration of 
Table IV. Adverse reactions in children with different disease courses [n (\%)].

\begin{tabular}{lcccc}
\hline Adverse reaction & $\begin{array}{c}\text { High-risk } \\
\text { group }(\mathrm{n}=67)\end{array}$ & $\begin{array}{c}\text { Moderate-risk } \\
\text { group }(\mathrm{n}=58)\end{array}$ & $\begin{array}{c}\text { Low-risk } \\
\text { group (n=82) }\end{array}$ & $\begin{array}{c}\text { F value } \\
\text { P-value }\end{array}$ \\
\hline Bone marrow suppression & $9(13.43)$ & $4(6.90)$ & $1(1.22)$ & 0.039 \\
Gastrointestinal reaction & $24(35.82)$ & $18(31.03)^{\mathrm{a}}$ & $11(13.41)^{\mathrm{a}}$ & 0.099 \\
Skin allergic reaction & $9(13.43)$ & $7(12.07)^{\mathrm{a}}$ & $2(2.44)^{\mathrm{a}}$ & 0.042 \\
Liver function injury & $5(7.46)$ & $3(5.17)$ & $2(2.44)$ & 0.962 \\
Respiratory tract reaction & $13(19.40)$ & $6(10.35)$ & $4(4.88)$ & 0.908 \\
Adverse reaction rate $(\%)$ & $60(89.55)$ & $38(65.52)^{\mathrm{a}}$ & $20(24.39)^{\mathrm{a}, \mathrm{b}}$ & 0.090 \\
\hline
\end{tabular}

${ }^{\mathrm{a}} \mathrm{P}<0.05$, compared with the low-risk group; ${ }^{\mathrm{b}} \mathrm{P}<0.05$, compared with the moderate-risk group.

B-lineage ALL children with different subtypes is significantly higher than that of T-lineage ALL children after $48 \mathrm{~h}$ of MTX infusion, and the incidence of adverse reactions of B-lineage ALL children is significantly higher than that of T-lineage ALL children, which indicates that MTX is less toxic and more suitable for T-lineage ALL children. The reason is presumed to be that methylene tetrahydrofolate reductase and $\gamma$-glutamyl transferase are very important metabolites during the treatment of MTX, and the higher their expression, the better metabolic circulation conditions of MTX in children (23). B-lineage ALL originates from B-lineage lymphocytes that are mainly distributed in human plasma, and belong to the first line of defense (24). The onset of B lymphoid causes the patient's plasma antibody ability to be in an extremely poor condition, and then the toxicity caused by the injection of MTX begins to invade the patient's blood, but the blood tissues cannot resist the toxicity of MTX and could only be counteracted by the injection of CF. Therefore, the toxic effect of MTX in vivo is greater than its metabolic effect, which results in higher plasma concentration in patients with B-lineage ALL. T-lineage ALL originates from T-lineage lymphocytes that are mainly distributed in the cell membrane and play a role in immune metabolism through surface antigen and surface receptor (25). Therefore, the immune metabolic function of B cells in patients can form the first filter device after the MTX injection, and the toxicity of MTX can be eliminated completely after CF injection, which indicates that MTX can directly undergo metabolic reactions for effective treatment after entering the cells of the patient. The results of Conter et al (26) in the study of high-dose MTX in ALL patients are consistent with this experiment. Among patients with different disease courses, we found that there is no significant difference in plasma concentration among the three groups at different time-points. Also, the adverse reaction rate in the high-risk group was found to be significantly higher than that in moderate- and low-risk groups, and in the moderate-risk group was significantly higher than that in the low-risk group. Moreover, the $\mathrm{CF}$ rescue times in high-risk group were found to be more than that in the other two groups, which suggested that high-dose MTX is more toxic to children with more severe disease. The cause may be that the disease course in the high-risk group is significantly higher than that in the other two groups, and the internal environment of children is severely damaged by leukemic cells, and is totally unable to resist the incidental toxicity of MTX injected into the body, and only continuous
CF rescue can neutralize the efficacy of MTX. Therefore, more attention should be paid to children with serious ALL in clinic. The vital signs of children should be paid close attention in order to prevent the toxic effect of MTX treatment from being greater than its efficacy and having a negative effect on the children.

The purpose of this study was to analyze the efficacy differences of high-dose MTX in ALL children with different subtypes and disease courses. However, because of the limited experimental conditions, there are still some shortcomings, such as the small base of the study subjects for statistical analysis. Also there may be differences in the results among different ethnic and age groups. Thus, further studies are still needed.

In conclusion, compared with T-lineage ALL children, high-dose MTX caused more toxic injury to B-lineage ALL children. During clinical application of MTX in the treatment of ALL, close attention should be paid to the changes of vital signs of patients, and timely $\mathrm{CF}$ rescue should be performed.

\section{Acknowledgements}

Not applicable.

\section{Funding}

No funding was received.

\section{Availability of data and materials}

The datasets used and/or analyzed during the current study are available from the corresponding author on reasonable request.

\section{Authors' contributions}

FG and QM were responsible for the treatment of the patients. $\mathrm{CL}$ and $\mathrm{YZ}$ analyzed the patient data and revised the manuscript. FG drafted the manuscript. All authors read and approved the final manuscript.

\section{Ethics approval and consent to participate}

This study was approved by the Ethics Committee of the People's Hospital of Pingyi County (Linyi, China). Signed informed consents were obtained from the guardians of the patients. 


\section{Patient consent for publication}

Not applicable.

\section{Competing interests}

The authors declare that they have no competing interests.

\section{References}

1. Wang W, Zimmerman G, Huang X, Yu S, Myers J, Wang Y, Moreton S, Nthale J, Awadallah A, Beck R, et al: Aberrant Notch signaling in the bone marrow microenvironment of acute lymphoid leukemia suppresses osteoblast-mediated support of hematopoietic niche function. Cancer Res 76: 1641-1652, 2016.

2. Nicolato A, Nouér SA, Garnica M, Portugal R, Maiolino A and Nucci M: Invasive fungal diseases in patients with acute lymphoid leukemia. Leuk Lymphoma 57: 2084-2089, 2016.

3. El-Jawahri A, Li S, Ballen KK, Cutler C, Dey BR, Driscoll J, Hunnewell C, Ho VT, McAfee SL, Poliquin C, et al: Phase II trial of reduced-intensity busulfan/clofarabine conditioning with allogeneic hematopoietic stem cell transplantation for patients with acute myeloid leukemia, myelodysplastic syndromes, and acute lymphoid leukemia. Biol Blood Marrow Transplant 22: 80-85, 2016.

4. Duque-Afonso J, Lin CH, Han K, Wei MC, Feng J, Kurzer JH, Schneidawind C, Wong SH, Bassik MCand Cleary ML: E2A-PBX1 remodels oncogenic signaling networks in B-cell precursor acute lymphoid leukemia. Cancer Res 76: 6937-6949, 2016.

5. Fitzgerald JC, Weiss SL, Maude SL, Barrett DM, Lacey SF Melenhorst JJ, Shaw P, Berg RA, June CH, Porter DL, et al: Cytokine release syndrome after chimeric antigen receptor $\mathrm{T}$ cell therapy for acute lymphoblastic leukemia. Crit Care Med 45 e124-e131, 2017.

6. Jacoby E, Nguyen SM, Fountaine TJ, Welp K, Gryder B, Qin H, Yang Y, Chien CD, Seif AE, Lei H, et al: CD19 CAR immune pressure induces B-precursor acute lymphoblastic leukaemia lineage switch exposing inherent leukaemic plasticity. Nat Commun 7: 12320, 2016

7. Frey NV and Porter DL: Cytokine release syndrome with novel therapeutics for acute lymphoblastic leukemia. Hematology (Am Soc Hematol Educ Program) 2016: 567-572, 2016.

8. Ferreri AJ, Cwynarski K, Pulczynski E, Ponzoni M, Deckert M, Politi LS, Torri V, Fox CP, Rosée PL, Schorb E, et al International Extranodal Lymphoma Study Group (IELSG): Chemoimmunotherapy with methotrexate, cytarabine, thiotepa, and rituximab (MATRix regimen) in patients with primary CNS lymphoma: Results of the first randomisation of the International Extranodal Lymphoma Study Group-32 (IELSG32) phase 2 trial. Lancet Haematol 3: e217-e227, 2016.

9. Larsen EC, Devidas M, Chen S, Salzer WL, Raetz EA, Loh ML, Mattano LA Jr, Cole C,Eicher A, Haugan M, et al: Dexamethasone and high-dose methotrexate improve outcome for children and young adults with high-risk B-acute lymphoblastic leukemia: A report from Children's Oncology Group Study AALL0232. J Clin Oncol 34: 2380-2388, 2016.

10. Schmiegelow K, Attarbaschi A, Barzilai S, Escherich G, Frandsen TL, Halsey C, Hough R, Jeha S, Kato M, Liang DC, et al; Ponte di Legno toxicity working group: Consensus definitions of 14 severe acute toxic effects for childhood lymphoblastic leukaemia treatment: A Delphi consensus. Lancet Oncol 17: e231-e239, 2016.

11. Krull KR, Cheung YT, Liu W, Fellah S, Reddick WE, Brinkman TM, Kimberg C, Ogg R, Srivastava D, Pui CH, et al: Chemotherapy pharmacodynamics and neuroimaging and neurocognitive outcomes in long-term survivors of childhood acute lymphoblastic leukemia. J Clin Oncol 34: 2644-2653, 2016.

12. Asselin BL, Devidas M, Chen L, Franco VI, Pullen J, Borowitz MJ, Hutchison RE, Ravindranath Y, Armenian SH, Camitta BM, et al: Cardioprotection and safety of dexrazoxane in patients treated for newly diagnosed T-cell acute lymphoblastic leukemia or advanced-stage lymphoblastic non-Hodgkin lymphoma: A report of the Children's Oncology Group Randomized Trial Pediatric Oncology Group 9404. J Clin Oncol 34: 854-862, 2016.
13. Iparraguirre L, Gutierrez-Camino A, Umerez M, MartinGuerrero I, Astigarraga I, Navajas A, Sastre A, Garcia de Andoin $\mathrm{N}$ and Garcia-Orad A: MiR-pharmacogenetics of methotrexate in childhood B-cell acute lymphoblastic leukemia. Pharmacogenet Genomics 26: 517-525, 2016.

14. Wojtuszkiewicz A, Raz S, Stark M, Assaraf YG, Jansen G, Peters GJ, Sonneveld E, Kaspers GJ and Cloos J: Folylpolyglutamate synthetase splicing alterations in acute lymphoblastic leukemia are provoked by methotrexate and other chemotherapeutics and mediate chemoresistance. Int J Cancer 138: 1645-1656, 2016.

15. Jabbour E and Kantarjian H: Chronic myeloid leukemia: 2014 update on diagnosis, monitoring, and management. Am J Hematol 89: 547-556, 2014.

16. Burnett AK, Russell NH, Hills RK, Hunter AE, Kjeldsen L, Yin J, Gibson BE, Wheatley K and Milligan D: Optimization of chemotherapy for younger patients with acute myeloid leukemia: Results of the medical research council AML15 trial. J Clin Oncol 31: 3360-3368, 2013.

17. Hough R, Rowntree C, Goulden N, Mitchell C, Moorman A, Wade R and Vora A: Efficacy and toxicity of a paediatric protocol in teenagers and young adults with Philadelphia chromosome negative acute lymphoblastic leukaemia: Results from UKALL 2003. Br J Haematol 172: 439-451, 2016.

18. Hoelzer D, Bassan R, Dombret H, Fielding A, Ribera JM and Buske C; ESMO Guidelines Committee: Acute lymphoblastic leukaemia in adult patients: ESMO Clinical Practice Guidelines for diagnosis, treatment and follow-up. Ann Oncol 27 (Suppl 5): v69-v82, 2016

19. Liang DC, Yang CP, Liu HC, Jaing TH, Chen SH, Hung IJ, Yeh TC, Lin TH, Lai CL, Lai CY, et al: NUDT15 gene polymorphism related to mercaptopurine intolerance in Taiwan Chinese children with acute lymphoblastic leukemia. Pharmacogenomics J 16: 536-539, 2016.

20. Al-Ghobashy MA, Hassan SA, Abdelaziz DH, Elhosseiny NM, Sabry NA, Attia AS and El-Sayed MH: Development and validation of LC-MS/MS assay for the simultaneous determination of methotrexate, 6-mercaptopurine and its active metabolite 6-thioguanine in plasma of children with acute lymphoblastic leukemia: Correlation with genetic polymorphism. J Chromatogr B Analyt Technol Biomed Life Sci 1038: 88-94, 2016.

21. Howard SC, McCormick J, Pui CH, Buddington RK and Harvey RD: Preventing and managing toxicities of high-dose Methotrexate. Oncologist 21: 1471-1482, 2016.

22. Carbonnel F, Colombel JF, Filippi J, Katsanos KH, PeyrinBiroulet L, Allez M, Nachury M, Novacek G, Danese S, Abitbol V, et al; European Crohn's and Colitis Organisation; Groupe d'Étude Thérapeutique des Affections Inflammatoires Digestives: Methotrexate is not superior to placebo for inducing steroid-free remission, but induces steroid-free clinical remission in a larger proportion of patients with ulcerative colitis. Gastroenterology 150: 380-388.e4, 2016

23. Yamanaka H, Tanaka Y, Takeuchi T, Sugiyama N, Yuasa H, Toyoizumi S, Morishima Y, Hirose T and Zwillich S: Tofacitinib, an oral Janus kinase inhibitor, as monotherapy or with background methotrexate, in Japanese patients with rheumatoid arthritis: An open-label, long-term extension study. Arthritis Res Ther 18: 34, 2016.

24. Gitlin AD, von Boehmer L, Gazumyan A, Shulman Z, Oliveira TY and Nussenzweig MC: Independent roles of switching and hypermutation in the development and persistence of $\mathrm{B}$ lymphocyte memory. Immunity 44: 769-781, 2016.

25. Woessmann W, Seidemann K, Mann G, Zimmermann M, Burkhardt B, Oschlies I, Ludwig WD, Klingebiel T, Graf N, Gruhn B, et al; BFM Group: The impact of the methotrexate administration schedule and dose in the treatment of children and adolescents with B-cell neoplasms: A report of the BFM Group Study NHL-BFM95. Blood 105: 948-958, 2005.

26. Conter V, Valsecchi MG, Buldini B, Parasole R, Locatelli F, Colombini A, Rizzari C, Putti MC, Barisone E, Lo Nigro L, et al: Early T-cell precursor acute lymphoblastic leukaemia in children treated in AIEOP centres with AIEOP-BFM protocols: A retrospective analysis. Lancet Haematol 3: e80-e86, 2016.

This work is licensed under a Creative Commons Attribution-NonCommercial-NoDerivatives 4.0 International (CC BY-NC-ND 4.0) License. 